\title{
Relaxation of heavy species and gas temperature in the afterglow of a $\mathrm{N}_{2}$ microwave discharge ${ }^{\star}$
}

\author{
Carlos D. Pintassilgo ${ }^{1,2,{ }^{*}}$ and Vasco Guerra ${ }^{1}$ \\ ${ }^{1}$ Instituto de Plasmas e Fusão Nuclear, Instituto Superior Técnico, Universidade de Lisboa, 1049-001 Lisboa, Portugal \\ 2 Departamento de Engenharia Física, Faculdade de Engenharia, Universidade do Porto, R. Dr. Roberto Frias, \\ 4200-465 Porto, Portugal
}

Received: 21 June 2017 / Received in final form: 12 September 2017 / Accepted: 25 September 2017

\begin{abstract}
In this paper we present a self-consistent kinetic model to study the temporal variation of the gas temperature in the afterglow of a $440 \mathrm{~Pa}$ microwave nitrogen discharge operating at $433 \mathrm{MHz}$ in a $3.8 \mathrm{~cm}$ diameter tube. The initial conditions in the afterglow are determined by a kinetic model that solves the electron Boltzmann equation coupled to the gas thermal balance equation and a system of rate-balance equations for $\mathrm{N}_{2}\left(\mathrm{X}^{1} \sum_{\mathrm{g}}{ }^{+}, v\right)$ molecules, electronically excited states of $\mathrm{N}_{2}$, ground and excited states of atomic nitrogen and the main positive ions. Once the initial concentrations of the heavy species and gas temperature are known, their relaxation in the afterglow is obtained from the solutions to the corresponding time-dependent equations. Modelling predictions are found to be in good agreement with previously measured values for the concentrations of $\mathrm{N}\left({ }^{4} \mathrm{~S}\right)$ atoms and $\mathrm{N}_{2}(\mathrm{~A}$ ${ }^{3} \sum_{\mathrm{u}}{ }^{+}$) molecules, and the radially averaged gas temperature $T_{g}$ along the afterglow of a microwave discharge in $\mathrm{N}_{2}$ under the same working conditions. It is shown that gas heating in the afterglow comes essentially from the energy transfer involving non-resonant vibration-vibration $(\mathrm{V}-\mathrm{V})$ collisions between vibrationally excited nitrogen molecules, as well as from energy exchanges in vibration-translation $(\mathrm{V}-\mathrm{T})$ on $\mathrm{N}_{2}-\mathrm{N}$ collisions.
\end{abstract}

\section{Introduction}

This work consolidates recent modelling calculations we have undertaken in the study of gas heating mechanisms in pure nitrogen plasmas $[1,2]$ by considering now a direct comparison with experimental results obtained in the afterglow of a flowing $\mathrm{N}_{2}$ microwave discharge [3]. As a matter of fact, our previous simulations in pure $\mathrm{N}_{2}$ plasmas described the temporal evolution of the gas temperature and corresponding heating mechanisms by solving a system of rate-balance equations for the heavy species coupled to the gas thermal balance equation for a relatively wide range of values for the reduced electric field and electron density observed on a typical glow discharge [2], but considering only a qualitative comparison with experiment. In spite of the insight provided by those works regarding the timedependent energy transfer to the translational mode, a straightforward comparison with experimental measurements for the gas temperature is still missing. Here, we address this issue by adopting the working conditions reported in [3], where the temporal variation of the gas temperature was measured for afterglow times in the range $0.5-100 \mathrm{~ms}$. Hence, in the present calculations, the gas temperature is self-consistently calculated along the

\footnotetext{
${ }^{\star}$ Contribution to the topical issue "Plasma Sources and Plasma Processes (PSPP)", edited by Luis Lemos Alves, Thierry Belmonte and Tiberiu Minea

*e-mail: cdp@fe.up.pt
}

afterglow and compared to the corresponding experimental results [3]. Moreover, we present and discuss the temporal evolution of the main gas heating channels.

Other modelling works developed previously with the aim to study the nitrogen afterglow [4-6] often consider the gas temperature as an input parameter, either by considering different values for the discharge and postdischarge [4,5] or using experimental results [6]. It is worth noting that the kinetic model presented in [6] considers the same experimental conditions [3] we are adopting in this work. While the modelling results reported in $[6]$ were principally focused on a very detailed description of the time-dependent kinetics of heavy species, such as $\mathrm{N}\left({ }^{4} \mathrm{~S}\right)$, $\mathrm{N}_{2}\left(\mathrm{~A}^{3} \sum_{\mathrm{u}}{ }^{+}\right), \mathrm{N}_{2}\left(\mathrm{~B}^{3} \prod_{\mathrm{g}}\right)$ and $\mathrm{N}_{2}\left(\mathrm{a}^{\prime} \sum_{\mathrm{u}}\right)$, the main purpose of the present work is the theoretical study of the temporal variation of the gas temperature and its influence on the overall kinetics. To our knowledge, such a theoretical analysis on the afterglow has not been carried out before.

\section{Model}

Similarly to our previous papers on the afterglow of a microwave discharge [4-8] our calculations are based on a kinetic model involving two parts, one for the discharge, and another one for the afterglow, where the initial concentrations for the afterglow are the ones obtained in the active plasma region.

With respect to the discharge region, our model is similar to the one considered in [9], where we solve a steady-state kinetic model based on the solutions to the homogeneous 


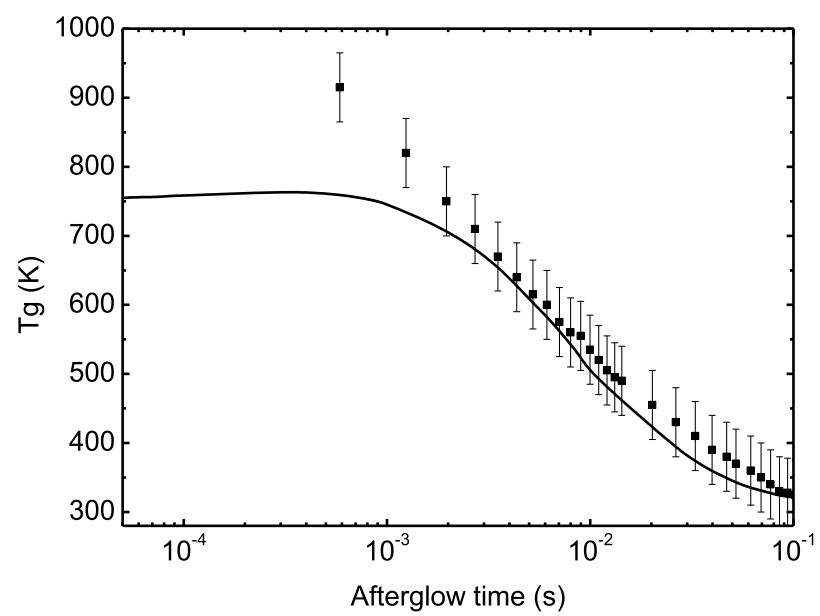

Fig. 1. Temporal variation of the radially averaged gas temperature $T_{g}$ (curve) in an afterglow of a flowing microwave discharge in $\mathrm{N}_{2}$ at $433 \mathrm{MHz}$ with $p=440 \mathrm{~Pa}$ in a tube diameter of $3.8 \mathrm{~cm}$. The radially averaged gas temperature measured in [3] is added for comparison (symbols) with error bars of $50 \mathrm{~K}$, as pointed out in that work.

electron Boltzmann equation for the microwave field coupled to a system of rate-balance equations for the most important species produced in the plasma, which include the vibrationally excited states of electronic ground state of molecular nitrogen $\mathrm{N}_{2}\left(\mathrm{X}^{1} \sum_{\mathrm{g}}{ }^{+}, v\right)$, the electronically excited states $\mathrm{N}_{2}\left(\mathrm{~A}^{3} \sum_{\mathrm{u}}{ }^{+}, \mathrm{B}^{3} \prod_{\mathrm{g}}, \mathrm{B}^{\prime} \sum_{\mathrm{u}}^{-}, \mathrm{C}^{3} \prod_{\mathrm{u}}, \mathrm{a}^{\prime 1} \sum_{\mathrm{u}}{ }^{-}, \mathrm{a}^{1} \prod_{\mathrm{g}}, \mathrm{w}^{1} \Delta_{\mathrm{u}}\right)$, both ground and excited states of atomic nitrogen $\mathrm{N}\left({ }^{4} \mathrm{~S},{ }^{2} \mathrm{D}\right.$, ${ }^{2} \mathrm{P}$ ) and the main positive ions $\mathrm{N}_{2}{ }^{+}$and $\mathrm{N}_{4}^{+}$. In these calculations, the high-frequency maintenance sustaining electric field in the plasma is self-consistently calculated for a cylindrical tube, imposing the quasi-neutrality condition and the requirement that under steady-state conditions the total rate of ionization must compensate exactly for the rate of electron loss by diffusion to the wall plus the electron-ion recombination. Additionally, as in [9], the gas thermal balance equation is incorporated in the system of equations. This equation determines the radially averaged gas temperature $T_{g}$ assuming a parabolic radial profile for the gas temperature and considering further that heat conduction is the main cooling mechanism. Furthermore, this equation must account for all available energy to gas heating (translational mode) from volume and wall processes, described with detail in [1,2,9-12].

In what concerns the afterglow region, once the stationary concentrations of the heavy species produced in the discharge and the gas temperature are calculated, we consider these values as initial conditions in a set of coupled time-dependent kinetic rate-balance equations, including the vibrational distribution function (VDF) of $\mathrm{N}_{2}(\mathrm{X}, v)$ molecules and all the other heavy-particles, solved simultaneously with the time-dependent gas thermal balance equation $[1,2]$.

To shorten this paper to an appropriate length, the reader should refer to references $[4-7,9,11]$ for more details on collisional data, modelling aspects concerning the electron Boltzmann equation, microwave discharge and post-discharge conditions, to references $[1,2,10,11]$ for additional information on gas heating mechanisms, gas thermal balance equation and energy data, as well as to [1,13-15] for the values of the molar heat capacity and thermal conductivity under non-equilibrium conditions.

\section{Results and discussion}

The present results have been obtained for the same experimental conditions considered in [3,6] corresponding to an afterglow of a flowing microwave discharge with a frequency of $433 \mathrm{MHz}$ produced in a $3.8 \mathrm{~cm}$ diameter Pyrex tube at a pressure of $440 \mathrm{~Pa}$. As in [6] we have used in our calculations a value of $3 \times 10^{10} \mathrm{~cm}^{-3}$ for the electron density in the discharge and beginning of the afterglow, corresponding to the one experimentally found in [3]. This value is slightly larger than the critical value for the electron density $1.17 \times 10^{10} \mathrm{~cm}^{-3}$, obtained from the condition $\omega_{p e}>\omega \sqrt{1+\epsilon_{g}}$, where $\omega_{p e}$ is the electron plasma angular frequency, considering a surface wave mode propagation with $\omega / 2 \pi=433 \mathrm{MHz}$ and a relative permittivity $\epsilon_{g}=4$ for a quartz tube.

It is worth noting that the measured values in [3] for the gas temperature along the afterglow are obtained from the rotational temperature of $\mathrm{N}_{2}\left(\mathrm{~A}^{3} \sum_{\mathrm{u}}{ }^{+}\right)$molecules (shown to be in equilibrium with the translational mode) by an intracavity laser absorption spectroscopy technique based on the attenuation of the near infrared laser radiation along the absorption path. Moreover, in the experiment undertaken in [3] the temperature of the tube wall $T_{w}$ has been simultaneously measured with an optical fibre temperature probe and found to decrease in the afterglow region from $420 \mathrm{~K}$ down to $300 \mathrm{~K}$, being still of the order of $\sim 350 \mathrm{~K}$ for an afterglow time of $15 \mathrm{~ms}$ (corresponding to an afterglow distance of $0.2 \mathrm{~m}$ under the conditions of [3]). Owing to the importance of this wall parameter on the gas cooling by heat conduction, we have accounted for this variation of $T_{w}$ on the gas thermal balance equation.

Figure 1 shows the results of our modelling predictions for the radially averaged gas temperature $T_{g}$ compared to the experimental measurements obtained in [3] along the afterglow of a microwave discharge with a frequency of $433 \mathrm{MHz}$ produced in a discharge tube with an inner diameter of $3.8 \mathrm{~cm}$ at $440 \mathrm{~Pa}$. We have also plotted in this figure error bars of $50 \mathrm{~K}$, corresponding to the experimental estimated accuracy reported in [3] for the values of the temperature. This figure reveals a very good agreement with experiment for afterglow times longer than $2 \mathrm{~ms}$, while the two first experimental points are higher than the predicted ones. Indeed, for an afterglow time of about $1 \mathrm{~ms}$, the experimental value of $T_{g}$ is $\sim 820 \mathrm{~K}$, while we compute a value of about $750 \mathrm{~K}$, being underestimated by $10 \%$. In addition, for an earlier afterglow time, a slightly larger discrepancy between modelling and experiment is observed in which the experimental value is about $900 \mathrm{~K}$, being about $150 \mathrm{~K}$ larger than our predictions. This corresponds to a difference of about $17 \%$. Before the analysis of this discrepancy, let us give a general overview of the heavy species kinetics in the afterglow.

Figure 2 depicts the temporal evolution of the most important gas heating mechanisms for the same conditions of Figure 1. The full curves report the reference results of 


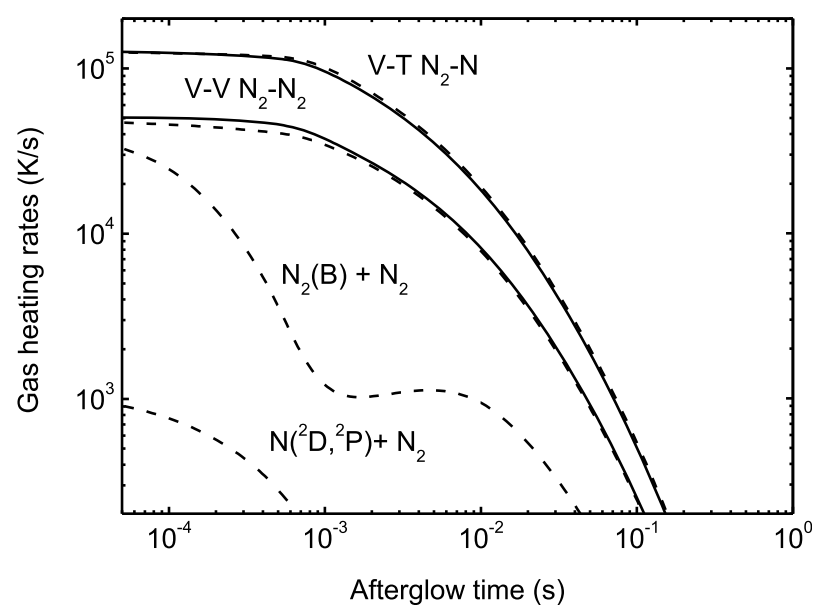

Fig. 2. Time-dependent variation of the heating rates of the most important gas heating mechanisms in an afterglow under the same conditions of Figure 1. The full curves (-) correspond to results of the reference model for $\mathrm{V}-\mathrm{T} \mathrm{N}_{2}-\mathrm{N}$ processes and nonresonant $\mathrm{V}-\mathrm{V} \mathrm{N} \mathrm{N}_{2}-\mathrm{N}_{2}$ processes, whereas the dashed curves (- - - ) describe the temporal evolution of the most relevant heating rates when $50 \%$ of the available energy from processes $\mathrm{N}_{2}$ (B) $+\mathrm{N}_{2} \rightarrow$ $\mathrm{N}_{2}(\mathrm{~A})+\mathrm{N}_{2}, \mathrm{~N}\left({ }^{2} \mathrm{D}\right)+\mathrm{N}_{2} \rightarrow \mathrm{N}\left({ }^{4} \mathrm{~S}\right)+\mathrm{N}_{2}$ and $\mathrm{N}\left({ }^{2} \mathrm{P}\right)+\mathrm{N}_{2} \rightarrow \mathrm{N}$ $\left({ }^{4} \mathrm{~S}\right)+\mathrm{N}_{2}$ is transferred to gas heating (only discussed in the text after Fig. 5).

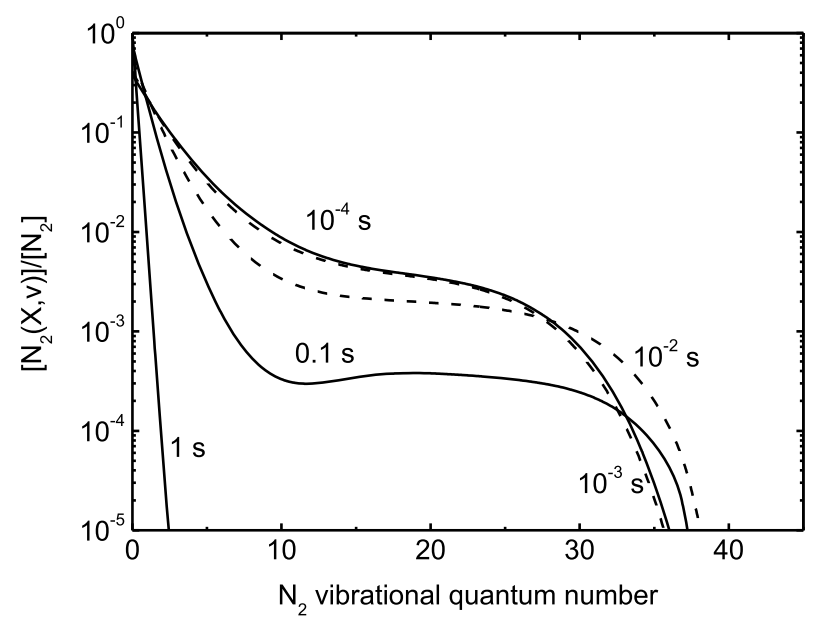

Fig. 3. Temporal evolution of the vibrational distribution function $\left[\mathrm{N}_{2}(\mathrm{X}, v)\right] /\left[\mathrm{N}_{2}\right]$ during an afterglow of a flowing microwave discharge in $\mathrm{N}_{2}$ at $433 \mathrm{MHz}$ with $p=440 \mathrm{~Pa}$ in a tube diameter of $3.8 \mathrm{~cm}$.

our model when there is no energy transferred to gas heating from processes $\mathrm{N}_{2}(\mathrm{~B})+\mathrm{N}_{2} \rightarrow \mathrm{N}_{2}(\mathrm{~A})+\mathrm{N}_{2}, \mathrm{~N}$ $\left({ }^{2} \mathrm{D}\right)+\mathrm{N}_{2} \rightarrow \mathrm{N}\left({ }^{4} \mathrm{~S}\right)+\mathrm{N}_{2}$ and $\mathrm{N}\left({ }^{2} \mathrm{P}\right)+\mathrm{N}_{2} \rightarrow \mathrm{N}\left({ }^{4} \mathrm{~S}\right)+\mathrm{N}_{2}$, while the dashed curves indicate the contribution to gas heating when $50 \%$ of the corresponding defect energy is transferred to the translational mode (to be discussed in this paper after Fig. 5). Figure 2 indicates that the total gas heating rate comes principally from non-resonant energy exchanges vibration-vibration $(\mathrm{V}-\mathrm{V})$ between two vibrationally excited $\mathrm{N}_{2}$ molecules and from vibration-translation ( $\mathrm{V}-\mathrm{T}$ ) energy transfer from collisions between vibrationally excited $\mathrm{N}_{2}$ molecules and nitrogen atoms.

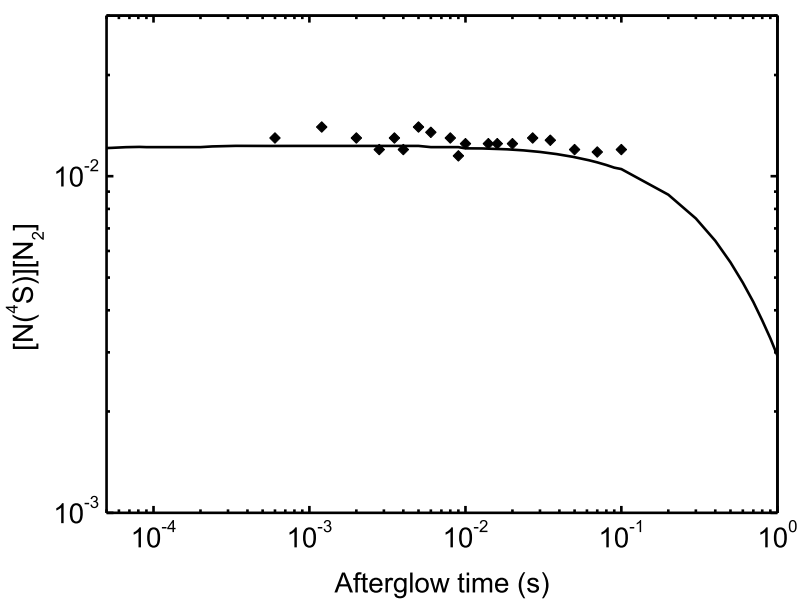

Fig. 4. Temporal variation of $\left[\mathrm{N}\left({ }^{4} \mathrm{~S}\right)\right] /\left[\mathrm{N}_{2}\right]$ (curve) in an afterglow of a flowing microwave discharge in $\mathrm{N}_{2}$ at $433 \mathrm{MHz}$ with $p=440 \mathrm{~Pa}$ in a tube diameter of $3.8 \mathrm{~cm}$. The corresponding experimental measurements (symbols) reported in [3] are added for comparison.

The heating rates of these two gas heating channels remain practically unchanged during the first millisecond of the afterglow, which explains the almost constant value for $T_{g}$ in during this time interval, where the shape of the VDF and $\left[N\left({ }^{4} \mathrm{~S}\right)\right]$ (see Figs. 3 and 4 ) remain nearly the same. For longer afterglow times, the value of the radially averaged gas temperature starts to decrease as a consequence of lower gas heating rates from these two processes. There is a smooth decrease of the gas temperature until an afterglow time of $10 \mathrm{~ms}$, where $T_{g}$ is still of the order of $500 \mathrm{~K}$, when a significant $\mathrm{V}-\mathrm{V}$ up-pumping occurs. At this time, the tail of the VDF passes through a maximum (see Fig. 3). Finally, for afterglow times longer than $100 \mathrm{~ms}$, the gas temperature definitely decreases down to $300 \mathrm{~K}$, having the same value as the temperature of the wall. For this time range, the gas heating mechanisms come no longer from the energy stored on the vibrational mode, but to a small (and therefore not shown in Fig. 2) contribution from wall processes $\mathrm{N}_{2}(\mathrm{X}$, $v)+$ wall and $\mathrm{N}\left({ }^{4} \mathrm{~S}\right)+$ wall $($ see $[2,10,11]$ for more details concerning the description of these mechanisms as gas heating channels) with heating rates of about 900 and $80 \mathrm{~K} / \mathrm{s}$, respectively, for an afterglow time of $50 \mathrm{~ms}$, decreasing afterwards till the end of the afterglow.

It is interesting to note that if all gas heating terms are removed from the gas thermal balance equation in the afterglow, remaining only the heat conduction term to the wall, the value of the gas temperature is about $500 \mathrm{~K}$ for an afterglow time of $1 \mathrm{~ms}$ and almost $300 \mathrm{~K}$ for afterglow times longer than $10 \mathrm{~ms}$. In the time range between $\sim 0.8$ and $20 \mathrm{~ms}$, these values are more than $100 \mathrm{~K}$ smaller than the ones reported in Figure 1.

For completeness, Figures 3-5 show, respectively, the temporal evolution of $\left[\mathrm{N}_{2}(\mathrm{X}, v)\right] /\left[\mathrm{N}_{2}\right],\left[\mathrm{N}\left({ }^{4} \mathrm{~S}\right)\right] /\left[\mathrm{N}_{2}\right]$ and $\left[\mathrm{N}_{2}(\mathrm{~A})\right] /\left[\mathrm{N}_{2}\right]$ in the afterglow under the same conditions of Figures 1 and 2. Figure 3 shows the typical time-dependent behaviour of the VDF in the afterglow, including the $\mathrm{V}-\mathrm{V}$ up-pumping effect mentioned above and the formation of Treanor plateaus. We have included in Figures 4 and 5 the corresponding experimental results presented in [3]. 


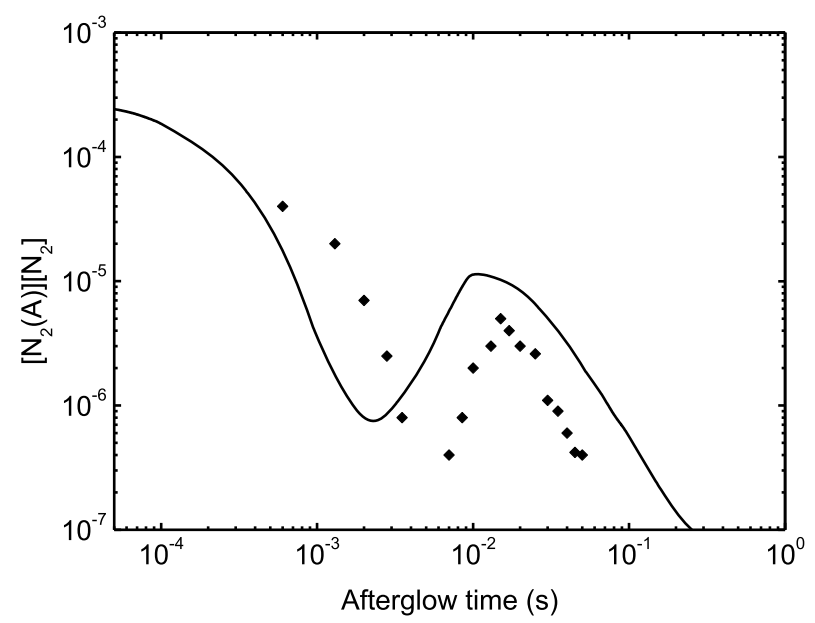

Fig. 5. As in Figure 4, but for $\left[\mathrm{N}_{2}(\mathrm{~A})\right] /\left[\mathrm{N}_{2}\right]$.

Figure 4 shows that the fractional concentration $\left[\mathrm{N}\left({ }^{4} \mathrm{~S}\right)\right] /$ $\left[\mathrm{N}_{2}\right]$ remains unchanged up to an afterglow time of almost $0.1 \mathrm{~s}$, in agreement with the experimental results. This effect, combined with the temporal evolution of the VDF leads to very important contributions to gas heating from $\mathrm{V}-\mathrm{T} \mathrm{N}_{2}-\mathrm{N}$ collisions, which is line with what we have observed previously $[1,2]$ for pulsed discharges. On the other hand, the predicted time-dependent behaviour obtained for $\left[\mathrm{N}_{2}(\mathrm{~A})\right] /\left[\mathrm{N}_{2}\right]$ shown in Figure 5 exhibits a reasonably good agreement with experiment. In particular, the relatively good (mainly qualitative, but also quantitative) predictions for $\mathrm{N}_{2}(\mathrm{~A})$ between 10 and $100 \mathrm{~ms}$ are a direct consequence of processes $\mathrm{N}_{2}(\mathrm{X}, v \geq 39)+\mathrm{N}\left({ }^{4} \mathrm{~S}\right) \rightarrow$ $\mathrm{N}_{2}(\mathrm{~A})+\mathrm{N}\left({ }^{2} \mathrm{D}\right)$, as discussed in [6]. However, for shorter afterglow times, our predicted values for $\left[\mathrm{N}_{2}(\mathrm{~A})\right]$ are underestimated, as in [6]. As pointed out in that work, this may result from the deactivation of the tail of the VDF by $\mathrm{V}-\mathrm{T}$ energy exchanges in $\mathrm{N}_{2}-\mathrm{N}$ collisions, decreasing then the formation of $\mathrm{N}_{2}(\mathrm{~A})$.

We return now to the comparison between model predictions and experiment for the radially averaged value of the gas temperature $T_{g}$ reported in Figure 1. That figure shows that modelling results are underestimated in the beginning of the afterglow, as a consequence of an underestimation of $T_{g}$ at the end of the discharge. This result may be due to the fact that in our reference calculations we have assumed that the available energy to gas heating from the three quenching processes $\mathrm{N}_{2}(\mathrm{~B})+\mathrm{N}_{2}$ $\rightarrow \mathrm{N}_{2}(\mathrm{~A})+\mathrm{N}_{2}, \mathrm{~N}\left({ }^{2} \mathrm{D}\right)+\mathrm{N}_{2} \rightarrow \mathrm{N}\left({ }^{4} \mathrm{~S}\right)+\mathrm{N}_{2}$ and $\mathrm{N}\left({ }^{2} \mathrm{P}\right)+\mathrm{N}_{2}$ $\rightarrow \mathrm{N}\left({ }^{4} \mathrm{~S}\right)+\mathrm{N}_{2}$, being respectively $1.18,2.38$ and $3.58 \mathrm{eV}$ is only transferred to vibrational excitation without any energy release into gas heating.

As in our previous modelling works on gas heating in pure $\mathrm{N}_{2}$ plasmas [1,2] we have carried out sensitivity tests with the purpose to analyse the effect of considering different percentages of these energy values channelled to gas heating on the value of $T_{g}$. Note that this kind of analysis has been also undertaken recently $[16,17]$ in the study of nanosecond pulsed discharges in nitrogen and air in order to explain the magnitude of experimental values for the gas temperature. In the present work, we have checked the variation of $T_{g}$ when $50 \%$ or $100 \%$ of the available energy from those three quenching processes is transferred into gas heating. These modelling tests have shown that the value of $T_{q}$ in the discharge increases from $750 \mathrm{~K}$ up to 768 and $788 \mathrm{~K}$, respectively. Hence, on the limit situation of having all the energy from those quenching processes entirely transferred to gas heating, the aforementioned observed discrepancy for the earlier afterglow time decreases respectively from $17 \%$ to $12 \%$.

This behaviour can be explained by the analysis of the dashed curves of Figure 2 reporting the temporal variation of the most relevant heating mechanisms when $50 \%$ of the available energy from processes $\mathrm{N}_{2}(\mathrm{~B})+\mathrm{N}_{2} \rightarrow \mathrm{N}_{2}(\mathrm{~A})+\mathrm{N}_{2}$, $\mathrm{N}\left({ }^{2} \mathrm{D}\right)+\mathrm{N}_{2} \rightarrow \mathrm{N}\left({ }^{4} \mathrm{~S}\right)+\mathrm{N}_{2}$ and $\mathrm{N}\left({ }^{2} \mathrm{P}\right)+\mathrm{N}_{2} \rightarrow \mathrm{N}\left({ }^{4} \mathrm{~S}\right)+\mathrm{N}_{2}$ is channelled to gas heating. While the contribution from $\mathrm{V}$ $\mathrm{T} \mathrm{N}_{2}-\mathrm{N}$ and $\mathrm{V}-\mathrm{V} \mathrm{N}_{2}-\mathrm{N}_{2}$ processes have essentially the same values obtained by the reference model (see full curves), the contribution to gas heating from the quenching of $\mathrm{N}_{2}(\mathrm{~B})$ by $\mathrm{N}_{2}$ for early afterglow times (corresponding basically to the situation verified in the discharge) is more than one order of magnitude lower than the contribution from the energy stored on the vibrational mode. In addition, for longer afterglow times, the modelling predictions for the gas temperature correspond to those plotted in Figure 1, as the populations of $\mathrm{N}_{2}(\mathrm{~B}), \mathrm{N}\left({ }^{2} \mathrm{D}\right)$ and $\mathrm{N}\left({ }^{2} \mathrm{P}\right)$ decrease significantly during the afterglow.

One other important point to be analysed involves also the quenching process $\mathrm{N}\left({ }^{2} \mathrm{D}\right)+\mathrm{N}_{2} \rightarrow \mathrm{N}\left({ }^{4} \mathrm{~S}\right)+\mathrm{N}_{2}$, which has a rate coefficient given by $10^{-13} \exp \left(-510 / T_{g}\right) \mathrm{cm}^{3} \mathrm{~s}^{-1}$ $[1,11]$ in our calculations. As a matter of fact, it has been recently pointed out in the study of nanosecond discharges in nitrogen [17] that the recent theoretical calculations dedicated to the estimation of the rate coefficient for this reaction $[18,19]$ propose a value given by $4.52 \times 10^{-14} T_{g}^{0.678} \exp \left(-1437.7 / T_{g}\right) \mathrm{cm}^{3} \mathrm{~s}^{-1}$, which leads to larger values for this rate coefficient. For instance, for the typical values $T_{g}=500$ and $750 \mathrm{~K}$, this expression provides rate coefficients that are respectively four or ten times larger than the ones we have been using in the reference model. Such stronger temperature dependence was shown to be essential to reconcile model predictions with experimental data in [17]. Therefore, we have also checked the impact of this larger rate coefficient on the present simulations. Modelling results reveal (not shown in a figure) a slight increase in the concentration of nitrogen atoms, where $\left[\mathrm{N}\left({ }^{4} \mathrm{~S}\right)\right] /\left[\mathrm{N}_{2}\right]$ is found to be almost constant, $\sim 0.013$ (in a good agreement with experiment), until an afterglow time of $10 \mathrm{~ms}$. This result is a direct consequence of a more efficient quenching of $\mathrm{N}\left({ }^{2} \mathrm{D}\right)$ by $\mathrm{N}_{2}$. In what concerns the gas temperature, the predicted value for this parameter increases by $\sim 5 \mathrm{~K}$ with respect to the reference case. Therefore, we can conclude that a modification in the rate coefficient considering this eventual update on the rate coefficients has a minor impact on the present calculations.

A combined analysis of Figures 1 and 5 shows that the predicted values for the gas temperature are underestimated in the end of the discharge and consequently in the beginning of the afterglow and at the same time the predicted results for $\left[\mathrm{N}_{2}(\mathrm{~A})\right]$ are lower than the experimental ones. This raises the possibility of an interplay between $\mathrm{N}_{2}(\mathrm{~A})$ and gas temperature, which indeed occurs through 
the pooling reactions $\mathrm{N}_{2}(\mathrm{~A})+\mathrm{N}_{2}(\mathrm{~A}) \rightarrow \mathrm{N}_{2}(\mathrm{~B})+\mathrm{N}_{2}$ and $\mathrm{N}_{2}(\mathrm{~A})+\mathrm{N}_{2}(\mathrm{~A}) \rightarrow \mathrm{N}_{2}(\mathrm{C})+\mathrm{N}_{2}$, which have an available energy to gas heating of $\sim 4$ and $0.4 \mathrm{eV}$, respectively [1,2]. As in our previous works, we have taken into account this gas heating mechanism. However, the present calculations have shown that this process plays only a minor on gas heating in the end of the discharge, as well as along the afterglow. Hence, under the conditions of this work, the main contribution from energy stored in the electronic degrees of freedom comes from processes $\mathrm{N}_{2}(\mathrm{~B})+\mathrm{N}_{2} \rightarrow \mathrm{N}_{2}(\mathrm{~A})+\mathrm{N}_{2}, \mathrm{~N}\left({ }^{2} \mathrm{D}\right)+\mathrm{N}_{2} \rightarrow \mathrm{N}$ $\left({ }^{4} \mathrm{~S}\right)+\mathrm{N}_{2}$ and $\mathrm{N}\left({ }^{2} \mathrm{P}\right)+\mathrm{N}_{2} \rightarrow \mathrm{N}\left({ }^{4} \mathrm{~S}\right)+\mathrm{N}_{2}$.

It is also worth noting that the experimental data reported in [3] for $\mathrm{N}_{2}(\mathrm{~A})$ concern the vibrational levels $v=0-6$, while our calculations consider, instead, the total population for each electronically excited state. Hence, a state-to-state approach [20] with a specific description for $\mathrm{N}_{2}\left(\mathrm{~A}^{3} \sum_{\mathrm{u}}{ }^{+}, v\right)$ states as in [21] would provide more accurate predictions and consequently a better agreement with the measurements reported in [3] for $\mathrm{N}_{2}(\mathrm{~A}, v=0-6)$.

\section{Conclusions}

This paper shows that the gas temperature decreases smoothly along the afterglow of a microwave discharge in pure $\mathrm{N}_{2}$ as a result of non-resonant $\mathrm{V}-\mathrm{V}$ energy exchanges in $\mathrm{N}_{2}-\mathrm{N}_{2}$ collisions, as well as from $\mathrm{V}-\mathrm{T} \mathrm{N} \mathrm{N}_{2}-\mathrm{N}$ processes. This effect is mainly a consequence of the time-dependent behaviour of the vibrational distribution function (VDF) of $\mathrm{N}_{2}\left(\mathrm{X}^{1} \sum_{\mathrm{g}}{ }^{+}, v\right)$ molecules, together with the long-lived role played by $\mathrm{N}\left({ }^{4} \mathrm{~S}\right)$ atoms on the overall afterglow kinetics.

The agreement between modelling and measured values for the gas temperature is very good for afterglow times longer than $1 \mathrm{~ms}$. For earlier times, the results of our simulations are underestimated by $10-17 \%$. Modelling calculations have shown that these discrepancies may decrease when one considers different available energies to gas heating from volume processes involving the quenching of excited states such as $\mathrm{N}_{2}(\mathrm{~B}), \mathrm{N}\left({ }^{2} \mathrm{D}\right)$ and $\mathrm{N}\left({ }^{2} \mathrm{P}\right)$ by $\mathrm{N}_{2}$. Nevertheless, some discrepancies, most likely related with the calculations of the gas temperature in the discharge, still persist and require further investigation.

A good agreement between simulations and experiment is also found for $\mathrm{N}\left({ }^{4} \mathrm{~S}\right)$ and $\mathrm{N}_{2}\left(\mathrm{~A}^{3} \sum_{\mathrm{u}}{ }^{+}\right)$. This contributes to the validation of the present model. Since these two species depend on a reliable description of the VDF, which in turn affects the value of the gas temperature, we may conclude that our modelling results constitute an important and accurate tool to proceed with further research on the interdependence between the gas temperature and the VDF. Within this context, a key point consists in the detailed analysis about the role of the gas temperature on the $\mathrm{V}-\mathrm{V}$ up-pumping mechanism (whose rate coefficients depend on $T_{g}$ ) along the afterglow, and consequent influence on the heavy species kinetics. Having validated our model predictions for the gas temperature, future work will be dedicated to the analysis of the optimal physical conditions leading to the formation and enhancement of this effect.

AcknowledgementsThis work partially supported by Portuguese FCT - Fundacão para a Ciência e a Tecnologia, under Project UID/FIS $/ 50010 / 2013$.

\section{References}

1. C.D. Pintassilgo, V. Guerra, J. Phys. Chem. C 120, 21184 (2016)

2. C.D. Pintassilgo, V. Guerra, Plasma Sources Sci. Technol. 26, 055001 (2017)

3. N. Sadeghi, C. Foissac, P. Supiot, J. Phys. D: Appl. Phys. 34, 1779 (2001)

4. P.A. Sá, J. Loureiro, J. Phys. D: Appl. Phys. 30, 2320 (1997)

5. J. Loureiro, P.A. Sá, V. Guerra, J. Phys. D: Appl. Phys. 34, 1697 (2001)

6. P.A Sá, V. Guerra, J. Loureiro, N. Sadeghi, J. Phys. D: Appl. Phys. 37, 221 (2004)

7. C.D. Pintassilgo, J. Loureiro, V. Guerra, J. Phys. D: Appl. Phys. 38, 417 (2005)

8. C.D. Pintassilgo, C. Jaoul, J. Loureiro, T. Belmonte, T. Czerwiec, J. Phys. D: Appl. Phys. 40, 3620 (2007)

9. V. Guerra, E. Tatarova, F.M. Dias, C.M. Ferreira, J. Appl. Phys. 91, 2648 (2002)

10. C.D. Pintassilgo, O. Guaitella, A. Rousseau, Plasma Sources Sci. Technol. 18, 025005 (2009)

11. V. Guerra, P.A. Sá, J. Loureiro, Eur. Phys. J. Appl. Phys. 28, $125(2004)$

12. C.D. Pintassilgo, S. Welzel, Eur. Phys. J. Appl. Phys. 76, $10801(2016)$

13. M. Capitelli, G. Colonna, D. Giordano, L. Marraffa, A. Casavola, P. Minelli, D. Pagano, L. Pietanza, F. Taccogna, J. Spacecr. Rockets 42, 980 (2005)

14. M. Capitelli, G. Colonna, C. Gorse, A.D. Angola, Eur. Phys. J. D 11, 279(2000)

15. W.Z. Wang, M.Z. Rong, J.D. Yan, A.B. Murphy, J.W. Spencer, Phys. Plasmas 18, 113502 (2011)

16. I. Shkurenkov, I.V. Adamovich, Plasma Sources Sci. Technol. 25, 015021 (2016)

17. N.D. Lepikhin, N.A. Popov, S.M. Starikovskaia, in: 23rd International Symposium on Plasma Chemistry (ISPC), Montréal, Canada, 2017

18. B.R.L. Galvão, A.J.C. Varandas, J.P. Braga, J.C. Belchior, J. Phys. Chem. Lett. 4, 2292 (2013)

19. B.R.L. Galvão, J.P. Braga, J.C. Belchior, A.J.C. Varandas, J. Chem. Theory Comput. 10, 1872 (2014)

20. N.A. Popov, J. Phys. D: Appl. Phys. 46, 355204 (2013)

21. M. Capitelli, I. Armenise, D. Bruno, M. Cacciatore, R. Celiberto, G. Colonna, O. De Pascale, P. Diomede, F. Esposito, C. Gorse, K. Hassouni, A. Laricchiuta, S. Longo, D. Pagano, D. Pietanza, M. Rutigliano, Plasma Sources Sci. Technol. 16, S30 (2007)

Cite this article as: Carlos D. Pintassilgo, Vasco Guerra, Relaxation of heavy species and gas temperature in the afterglow of a $\mathrm{N}_{2}$ microwave discharge, Eur. Phys. J. Appl. Phys. 80, 10803 (2017) 